\title{
Incidence and Survival of Childhood Cancer in Korea
}

Hyeon Jin Park, MD, PhD'1
Eun-Kyeong Moon, MPH²
Ju Young Yoon, MD, MS'
Chang-Mo Oh, MD, PhD²
Kyu-Won Jung, MS'
Byung Kiu Park, MD, PhD'
Hee Young Shin, MD, PhD³
Young-Joo Won, PhD²

${ }^{1}$ Center for Pediatric Oncology and

${ }^{2}$ Cancer Registration and Statistics Branch,

National Cancer Center, Goyang,

${ }^{3}$ Department of Pediatrics,

Seoul National University

College of Medicine, Seoul, Korea
Correspondence: Hee Young Shin, MD, PhD Department of Pediatrics,

Seoul National University College of Medicine, 101 Daehak-ro, Jongno-gu, Seoul 03080, Korea Tel: 82-2-2072-2917

Fax: 82-2-3675-0999

E-mail: hyshin@snu.ac.kr

Co-correspondence: Young-Joo Won, PhD Cancer Registration and Statistics Branch, National Cancer Center, 323 Ilsan-ro,

Ilsandong-gu, Goyang 10408, Korea

Tel: 82-31-920-2015

Fax: 82-31-920-2179

E-mail: astra67@ncc.re.kr

Received August 2, 2015

Accepted November 7, 2015

Published Online January 21, 2016

\section{Purpose}

An epidemiologic study of childhood cancer would provide useful information on cancer etiology and development of management guidelines.

\section{Materials and Methods}

Data from the Korea National Cancer Incidence Database were used to examine the incidence and survival of cancer in patients aged 0-14 years. Patients were grouped according to the International Classification of Childhood Cancer, 3rd edition. Age-specific and agestandardized incidences per million and estimated annual percentage change (APC) were calculated by sex and age. Five-year relative survival was calculated for four periods from 1993 to 2011.

\section{Results}

The study comprised 15,113 patients with malignant neoplasms. Age-standardized incidence rates for all cancers were 134.9 per million children in 1999-2011 and 144.0 and 124.9 per million for males and females, respectively (M/F ratio, 1.2; $p<0.05$ ). The highest incidences were observed for 'leukemias, myeloproliferative diseases, and myelodysplastic diseases' (group I) (46.4), 'central nervous system neoplasms' (group III) (18.3), and 'lymphomas and reticuloendothelial neoplasms' (group II) (13.4). Age-standardized incidence increased from 117.9 in 1999 to 155.3 in 2011, with an APC of 2.4\% (95\% confidence interval, 2.1 to 2.7). There was a significant increase of APC in 'neuroblastoma and other peripheral nervous cell tumors' (group IV) (5.6\%) and 'other malignant epithelial neoplasms and malignant melanomas' (group XI) (5.6\%). The 5-year relative survival rate for all childhood cancers improved significantly from 56.2\% (1993-1995) to 78.2\% (2007-2011) (males, $56.7 \%$ to $77.7 \%$; females, $55.5 \%$ to $78.8 \%$ ).

\section{Conclusion}

This study provides reliable information on incidence and survival trends for childhood cancer in Korea.

\section{Introduction}

The incidence of cancer in children younger than 15 years of age varies among countries worldwide. Despite dramatic
Key words

Neoplasms, Child, Incidence, Survival, Korea 
lion children have been reported [2-4]. According to a GLOBOCAN estimation of cancer rates in 2012, leukemia was the most common childhood malignancy worldwide, followed by malignancies of the brain and nervous system, non-Hodgkin lymphomas, renal tumors, and Hodgkin lymphomas. However, the rank and outcome of the most common cancer types varied among countries.

Cancer is also the second leading cause of childhood death in Korea. However, an epidemiologic study of cancer in children aged 0-14 years has never been conducted. We conducted the first nationwide study describing the incidence and survival of all childhood cancers in Korea.

\section{Materials and Methods}

\section{Data sources}

This study was approved by the Institutional Review Board (NCC 2015-0069). Data on childhood cancer incidence and survival in Korea were obtained from the Korea National Cancer Incidence database in the Korea Central Cancer Registry (KCCR).

The KCCR was initiated by the Korean Ministry of Health and Welfare in 1980 and collected cancer cases from more than 180 hospitals in Korea annually until 1998. These data represent $80 \%-90 \%$ of cancer incidence in Korea and have been collected on the entire Korean population since 1999 through a population-based cancer registry program [5].

The KCCR collects data on variables including age, sex, first diagnosis date, primary tumor site, morphology, method of diagnosis, and stage at diagnosis. KCCR statistics from 1999-2002 and 2003-2007 have been published in Cancer Incidence in Five Continents volumes IX and X (http://ci5.iarc. fr / Default.aspx), in which the completeness and validity of the incidence data were assessed.

The incidence rates of cancer in children aged 0-14 years who were diagnosed in 1999-2011 were calculated. For estimation of cancer survival, data on childhood cancer in 19932011 were obtained from the KCCR, and patients' vital status was followed up until December 31, 2012.

\section{Case definition}

To enable comparison with several previous studies of childhood cancer, the age group in this study was 0-14 years old [6-8]. Diagnoses were grouped into 12 main diagnostic groups and 47 subgroups according to the International Classification of Childhood Cancer, 3rd edition (ICCC-3) [9], which is based on the International Classification of Disease for Oncology, 3rd edition (ICD-O-3). The ICCC scheme, which is based on cancer topography and morphology, was specifically established for classification of tumors in children.

\section{Statistical methods}

\section{1) Incidence}

Frequencies, percent distribution, crude incidence rates and annual percent change (APC) were computed by sex and age group ( $<1$ year, 1-4 years, 5-9 years, and 10-14 years). Age-standardized incidence rates (ASRs) in males and females were estimated by the direct method using world standard population defined by the World Health Organization for age groups 0-14 years. The male/female ratio of the ASRs was also calculated. Cancer incidence trends were based on the APC, which was estimated using the following formula: $100 \times\left(e^{\beta}-1\right)$, where $\beta$ is the slope calculated from a linear regression of log ASRs in a calendar year (http:// seer.cancer.gov/csr/1975_2010/).

\section{2) Survival}

The 5-year survival rate for each diagnostic group was analyzed based on relative survival for the following time periods: 1993-1995, 1996-2000, 2001-2005, 2006-2010, and 2007-2011. These time periods were chosen to enable direct comparison with earlier studies [10,11]. The relative survival rates for each diagnostic group were calculated by dividing the observed survival by expected survival among comparable groups in the general population according to the Ederer II method. The survival rates were calculated by "complete analysis," which included "right-censored" patients. This analysis provided more up-to-date and precise survival rates in long-term survival, due to inclusion of the early survival experience of more recently recruited patients [12].

Trends in 5-year relative survival rates by time period were assessed using a relative excess risk model [13]. Statistical analyses were performed using SAS ver. 9.2 (SAS Institute Inc., Cary, NC).

\section{Results}

\section{Incidence}

A total of 15,113 cancer patients aged 0-14 years were diagnosed in 1999-2011, and the average annual incidence 
V. Retinoblastoma, $2.7 \%$
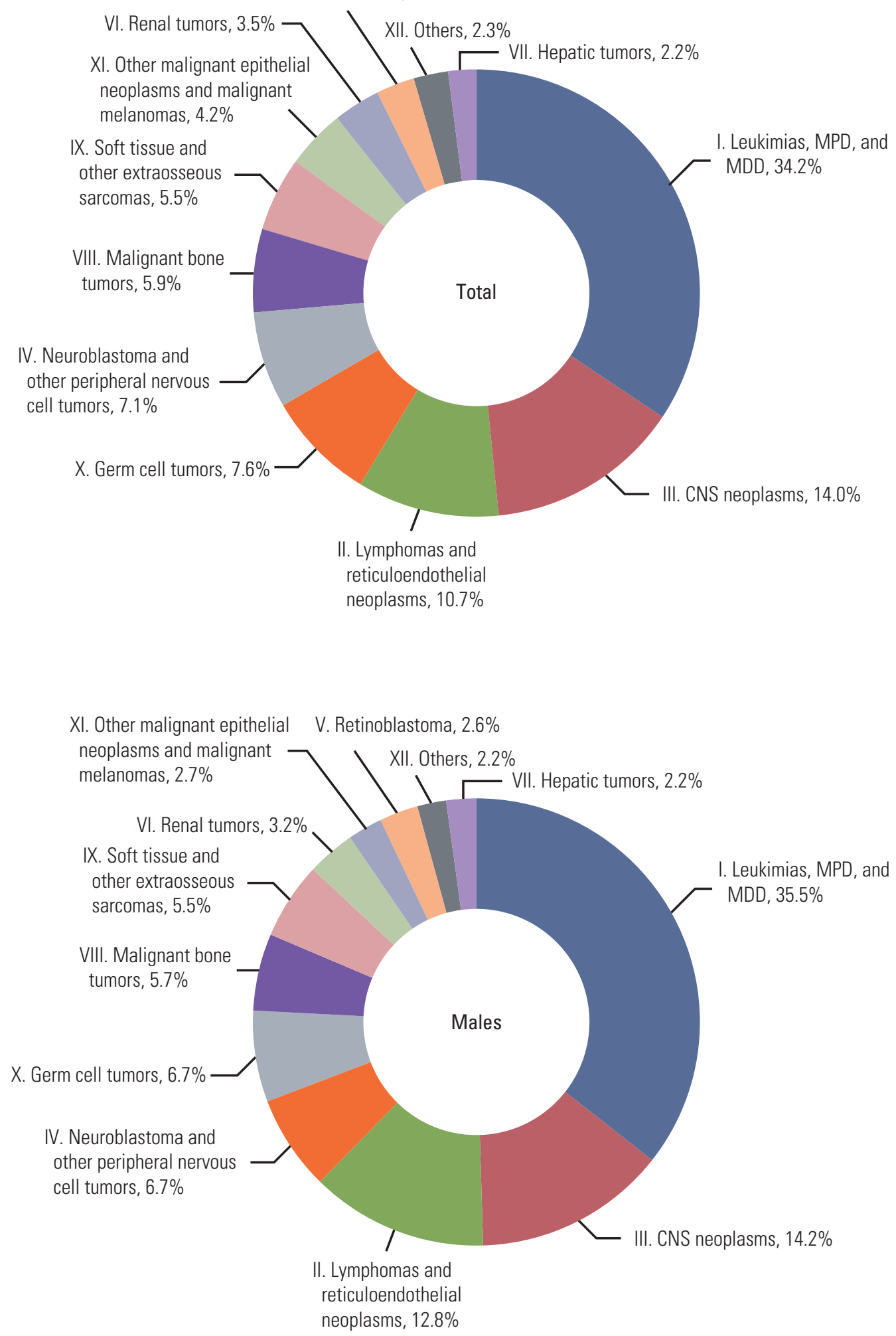

Fig. 1. Cancer incidence by diagnostic groups in children (0-14 years of age) in Korea, 1999-2011. MPD, myeloproliferative diseases; MDD, myelodysplastic diseases; CNS, central nervous system. (Continued to the next page) 


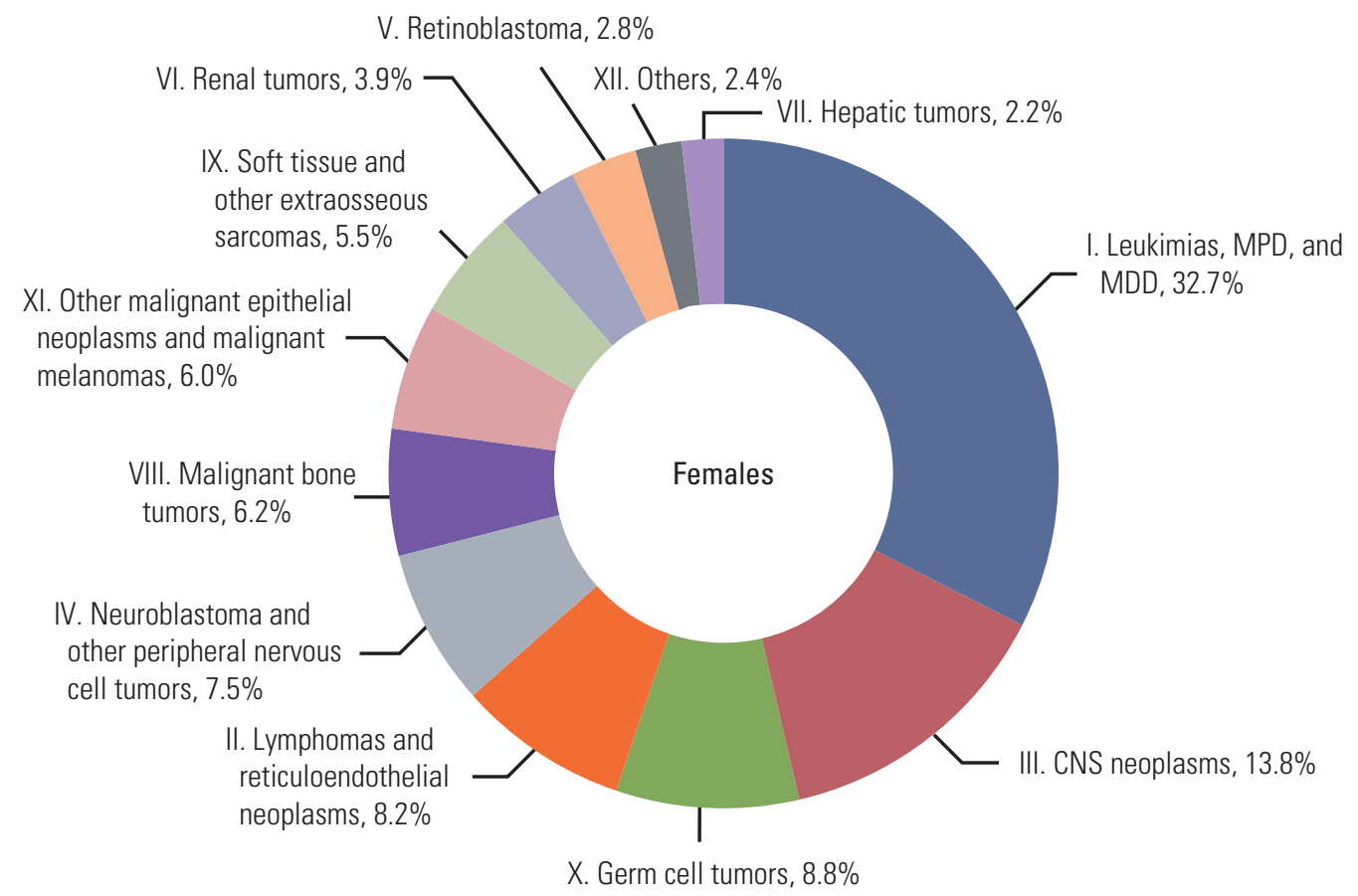

Fig. 1. (Continued from the previous page)

was 1,163 cases; 8,435 patients ( $55.8 \%$ ) were males, and 6,678 $(44.2 \%)$ were females. The age distribution was as follows: $<1$ year, 1,740 (11.5\%); 1-4 years, 4,694 (31.1\%); 5-9 years, $3,814(25.2 \%)$; and $10-14$ years, $4,865(32.2 \%)$. The most common cancer was 'leukemias, myeloproliferative diseases, and myelodysplastic diseases' (group I), which accounted for $34.2 \%$ of all cancers in both sexes (males, $35.5 \%$; females, $32.7 \%$ ); 'lymphoid leukemia' (group I.a) represented almost one third of this group. 'Leukemias, myeloproliferative diseases, and myelodysplastic diseases' (group I), 'central nervous system (CNS) neoplasms' (group III), and 'lymphomas and reticuloendothelial neoplasms' (group II) accounted for more than half of all childhood cancer cases (Fig. 1).

Between 1999 and 2011, the age-standardized incidence rate of all cancers was 144.0 and 124.9 per million for males and females, respectively. Higher cancer incidence was observed in males (male/female ratio, 1.2; $\mathrm{p}<0.05$ ). The higher rate among males was due to a substantially higher incidence of 'lymphomas and reticuloendothelial neoplasms' (group II) (male, 16.9 per million; female, 9.6 per million). The highest incidence rate was observed in children $<1$ year old (277.3 per million), followed by those aged 1-4 years (164.9 per million), 10-14 years (111.7 per million), and 5-9 years (92.8 per million) (Table 1 ). The higher rate among children $<1$ year old was largely due to a substantially higher incidence rate of 'leukemias, myeloproliferative diseases, and myelodysplastic diseases' (group I) (63.7 per million), 'neuroblastoma and other peripheral nervous cell tumors' (group IV) (55.6 per million) and CNS neoplasms (group III) (26.1 per million).

Incidence trends showed a significant increase between 1999 and 2011 (APC: 2.4\% per year in both sexes; 2.3\% per year in males; $2.6 \%$ per year in females) (Fig. 2). The incidence of most cancer types showed an increasing trend, with the exception of 'other and unspecified malignant neoplasms' (group XII) (APC, $-7.4 \%$; 95\% confidence interval [CI], -12.2 to -2.3$)$. There was a significant increase of APC in 'neuroblastoma and other peripheral nervous cell tumors' (group IV, 5.6\%) and 'other malignant epithelial neoplasms and malignant melanomas' (group XI, 5.6\%). However, in assessment by diagnostic group, the incidence of different cancer types varied between males and females. Among males, the highest increase in incidence was observed for 'other malignant epithelial neoplasms and malignant melanomas' (group XI) (APC, 6.1\%; 95\% CI, 1.1 to 11.3), followed by 'lymphomas and reticuloendothelial neoplasms' (group II) (APC, 4.8\% ; 95\% CI, 2.4 to 7.2) and 'neuroblastoma and other peripheral nervous cell tumors' (group IV) (APC, $4.3 \%$; $95 \%$ CI, 1.5 to 7.2 ). Among females, the highest increase in incidence was observed for 'neuroblastoma and other peripheral nervous cell tumors' (group IV) (APC, 7\%; 95\% CI, 4.9 to 9.3), followed by 'other malignant epithelial neo- 


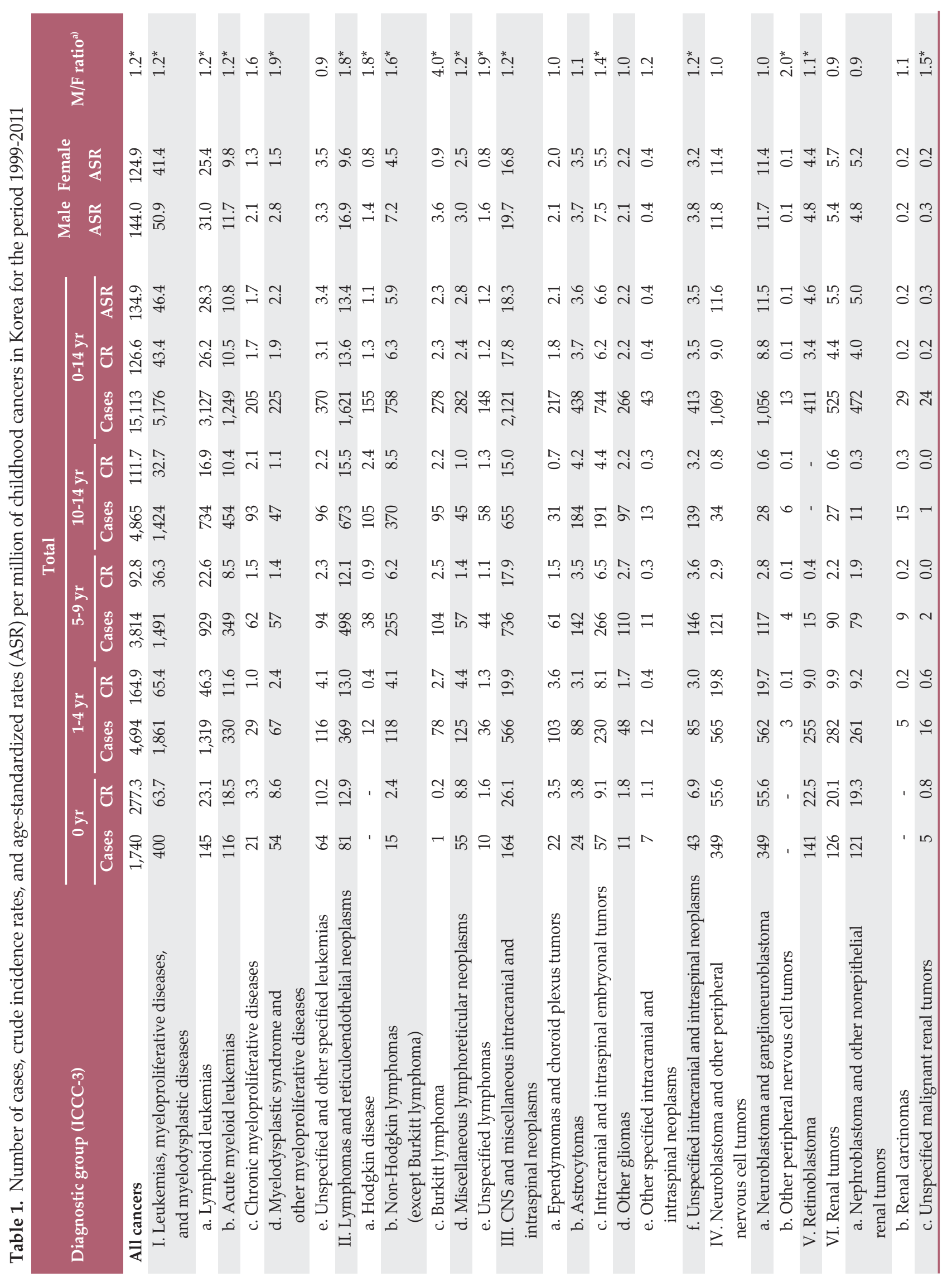




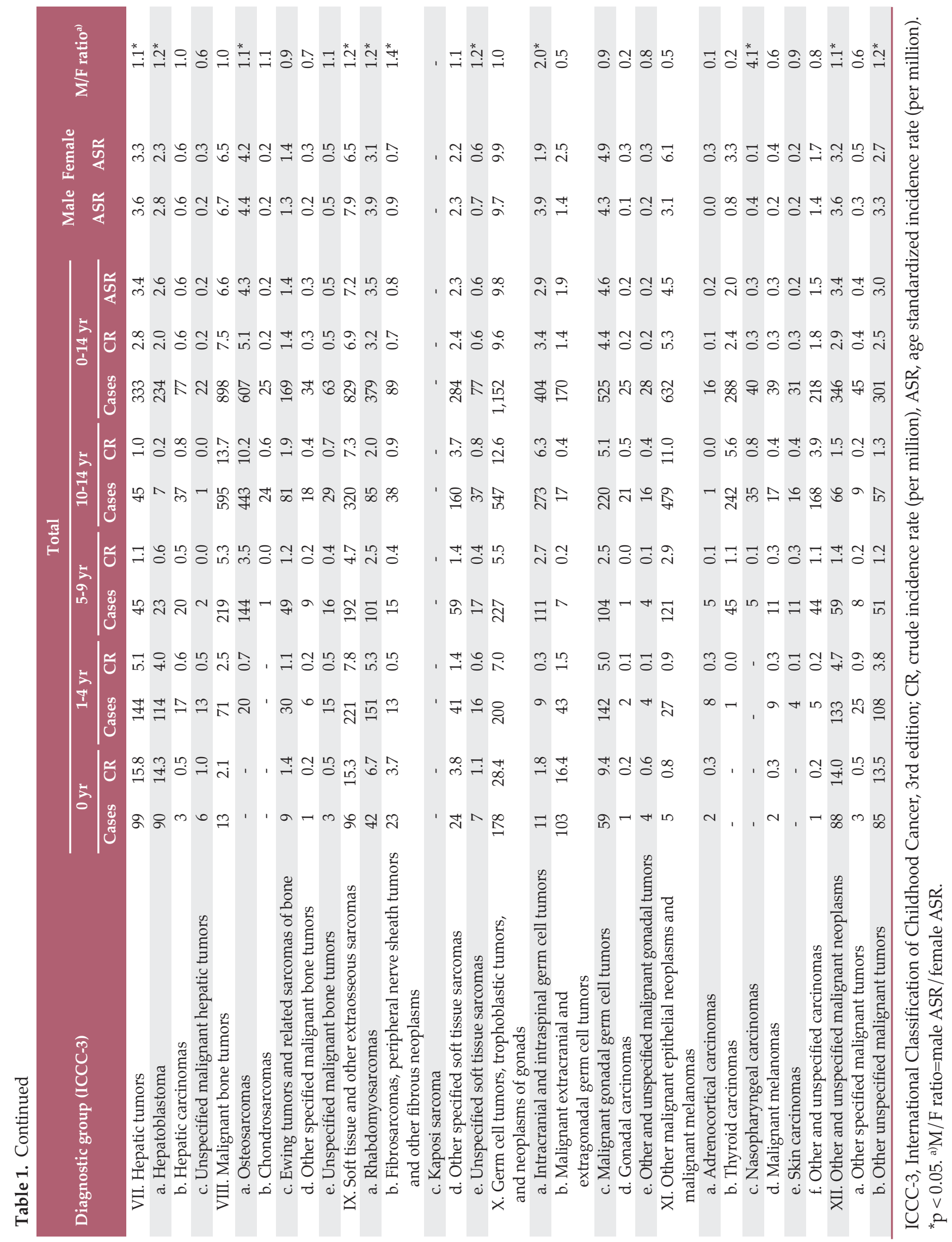




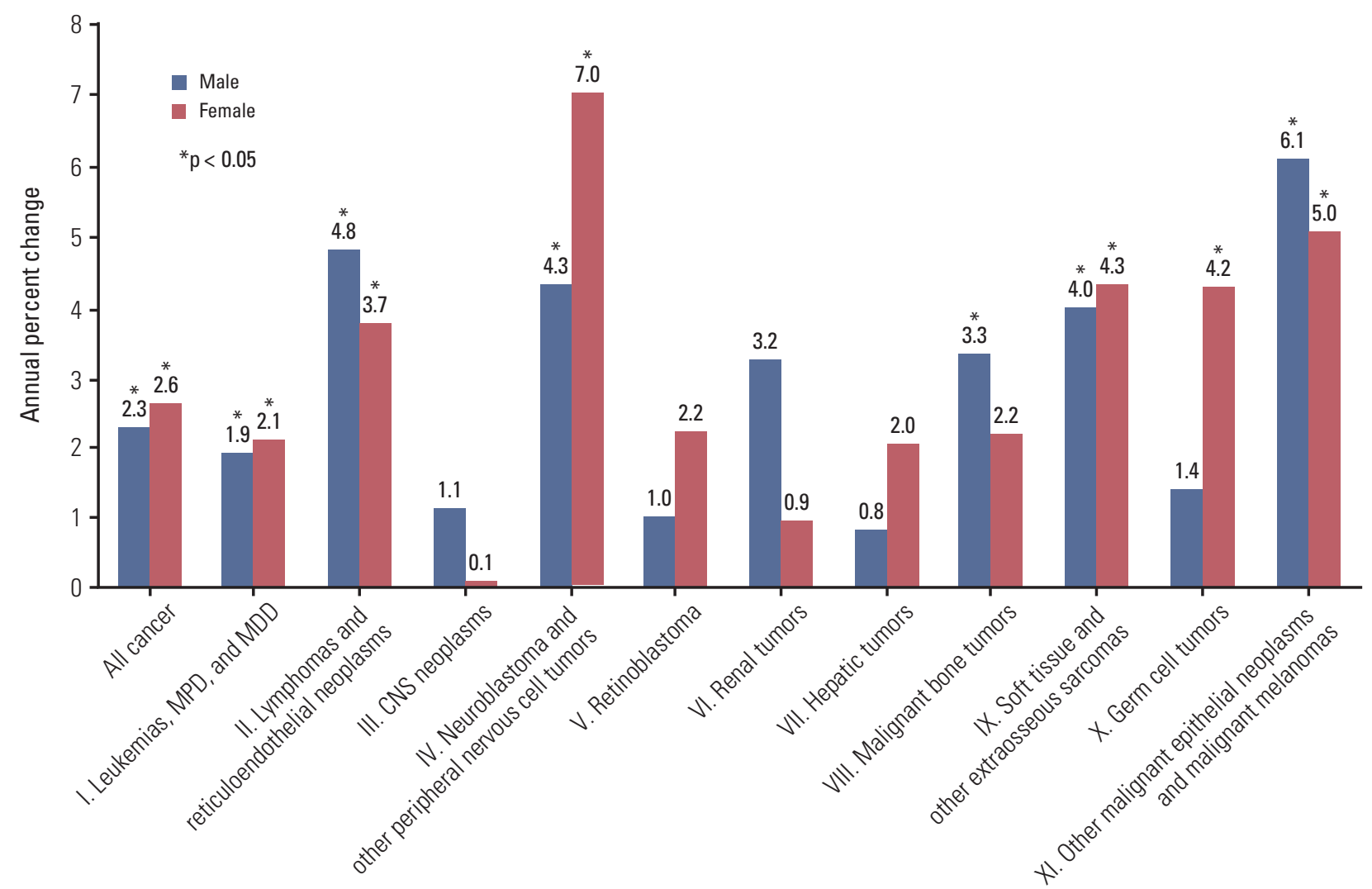

Fig. 2. Annual percent change of cancer incidence by diagnostic groups in children (0-14 years of age) in Korea, 1999-2011. MPD, myeloproliferative diseases; MDD, myelodysplastic diseases; CNS, central nervous system. * $\mathrm{p}<0.05$.

plasms and malignant melanomas' (group XI) (APC, 5\%; 95\% CI, -0.1 to 10.5$)$ and 'soft tissue and other extraosseous sarcomas' (group IX) (APC, 4.3\%; 95\% CI, 1.1 to 7.6) (Fig. 2).

\section{Survival}

The survival analysis comprised 20,523 children diagnosed with cancer in 1993-2011 (males, 11,644; females, 8,879). Table 2 shows the 5-year relative survival rates and the number of cases in each of the five time periods (1993-1995, 19962000, 2001-2005, 2006-2010, and 2007-2011). In analysis by 12 main diagnostic group, 'leukemias, myeloproliferative diseases, and myelodysplastic diseases' (group I) and 'neuroblastoma and other peripheral nervous cell tumors' (group IV) showed the most marked improvements in survival, from $47.4 \%$ and $43.2 \%$ in $1993-1995$ to $75.4 \%$ and $73.9 \%$ in 2007-2011, respectively. Survival rates for 'retinoblastoma' (group V) and 'other malignant epithelial neoplasms and malignant melanomas' (group XI) consistently exceeded $80 \%-90 \%$ for all periods measured. The lowest improvement in survival rate was observed for 'CNS neoplasms' (group III).

For all childhood cancers, the 5-year relative survival rate increased significantly, from 56.2\% in 1993-1995 to $78.2 \%$ in 2007-2011 ( $\mathrm{p}<0.05$ ), with significant improvements in both males (from 56.7\% in 1993-1995 to 77.7\% in 2007-2011; $\mathrm{p}<0.05$ ) and females (from $55.5 \%$ in $1993-1995$ to $78.8 \%$ in 2007-2011) ( $<$ 0.05) and for all age groups tested (Fig. 3). The improvement in the 5-year relative survival rate was slightly higher for females $(23.3 \%)$ compared with males $(21.0 \%)$. Among males, 5-year relative survival improved from $60.6 \%$ in $1993-1995$ to $76.4 \%$ in $2007-2011$ in children aged $<1$ year, from $54.9 \%$ to $82.9 \%$ in children aged $1-4$ years, from $52.0 \%$ to $77.0 \%$ in children aged $5-9$ years, and from $54.0 \%$ to $75.4 \%$ in children aged $10-14$ years. Among females, 5-year relative survival improved from $48.6 \%$ in 1993-1995 to $73.5 \%$ in $2007-2011$ in children aged $<1$ year, from $53.1 \%$ to $77.6 \%$ in children aged $1-4$ years, from $55.0 \%$ to $76.6 \%$ in children aged 5-9 years, and from $56.1 \%$ to $80.3 \%$ in children aged 10-14 years (Fig. 3). 


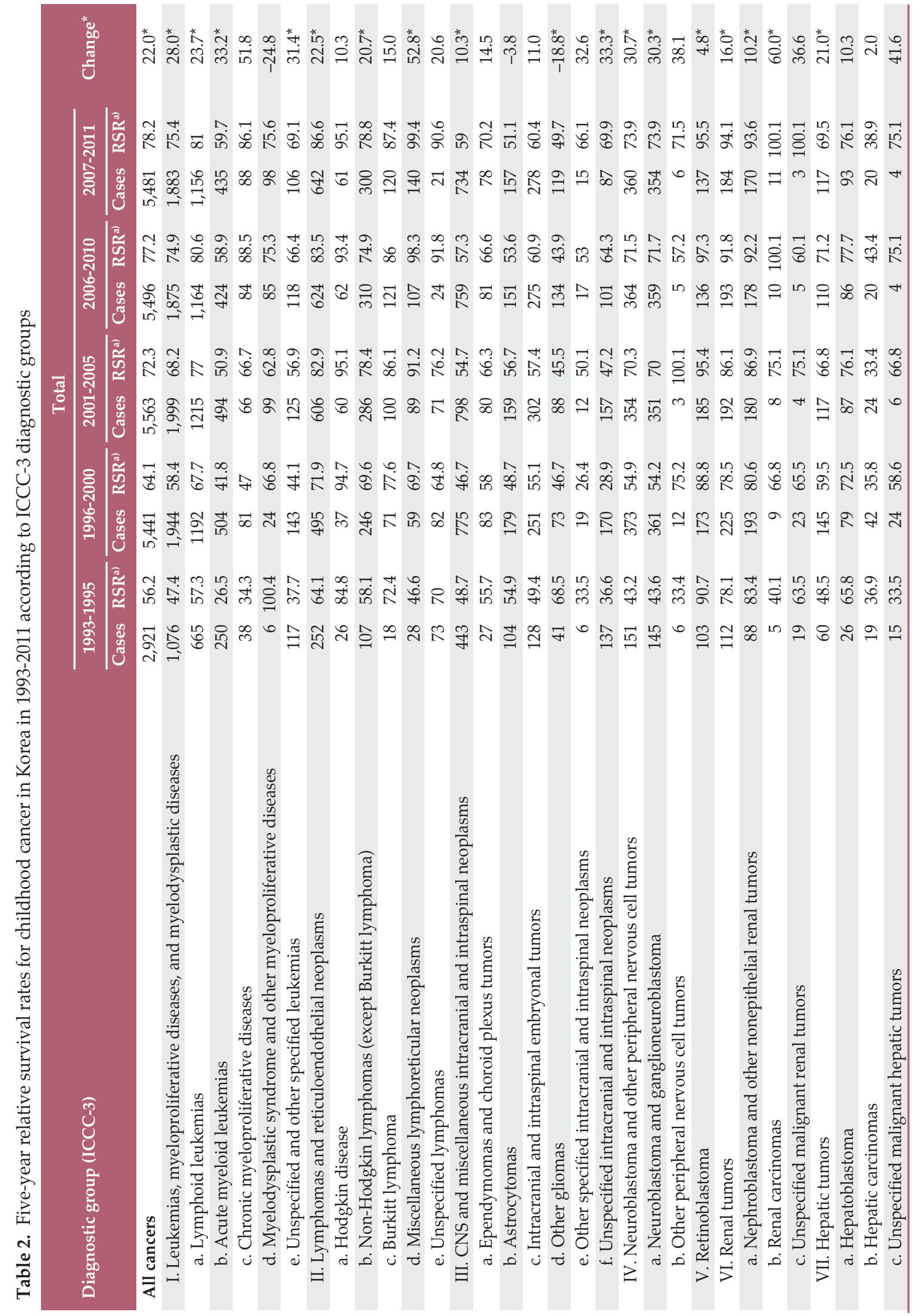


*

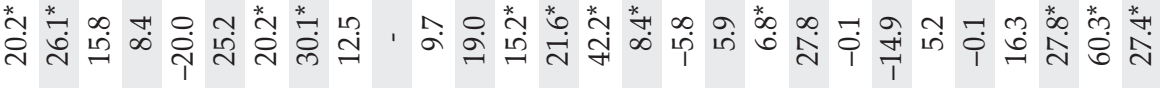

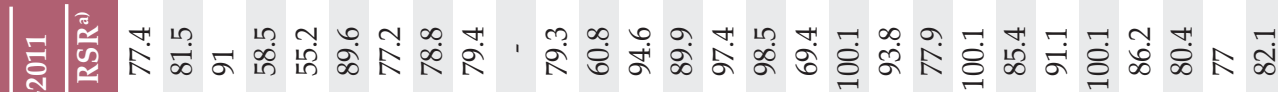

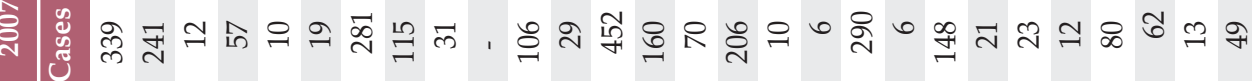
을 유 岗 零

롱 ॠ

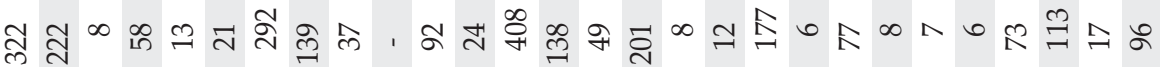

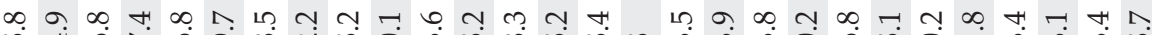
பु சु ๙ิ่

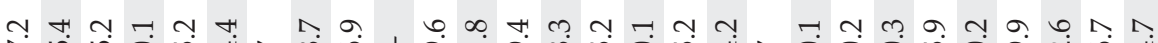
을

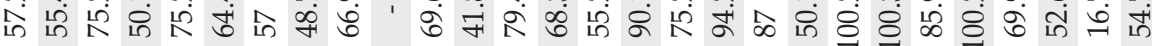
夰 ๙ิ
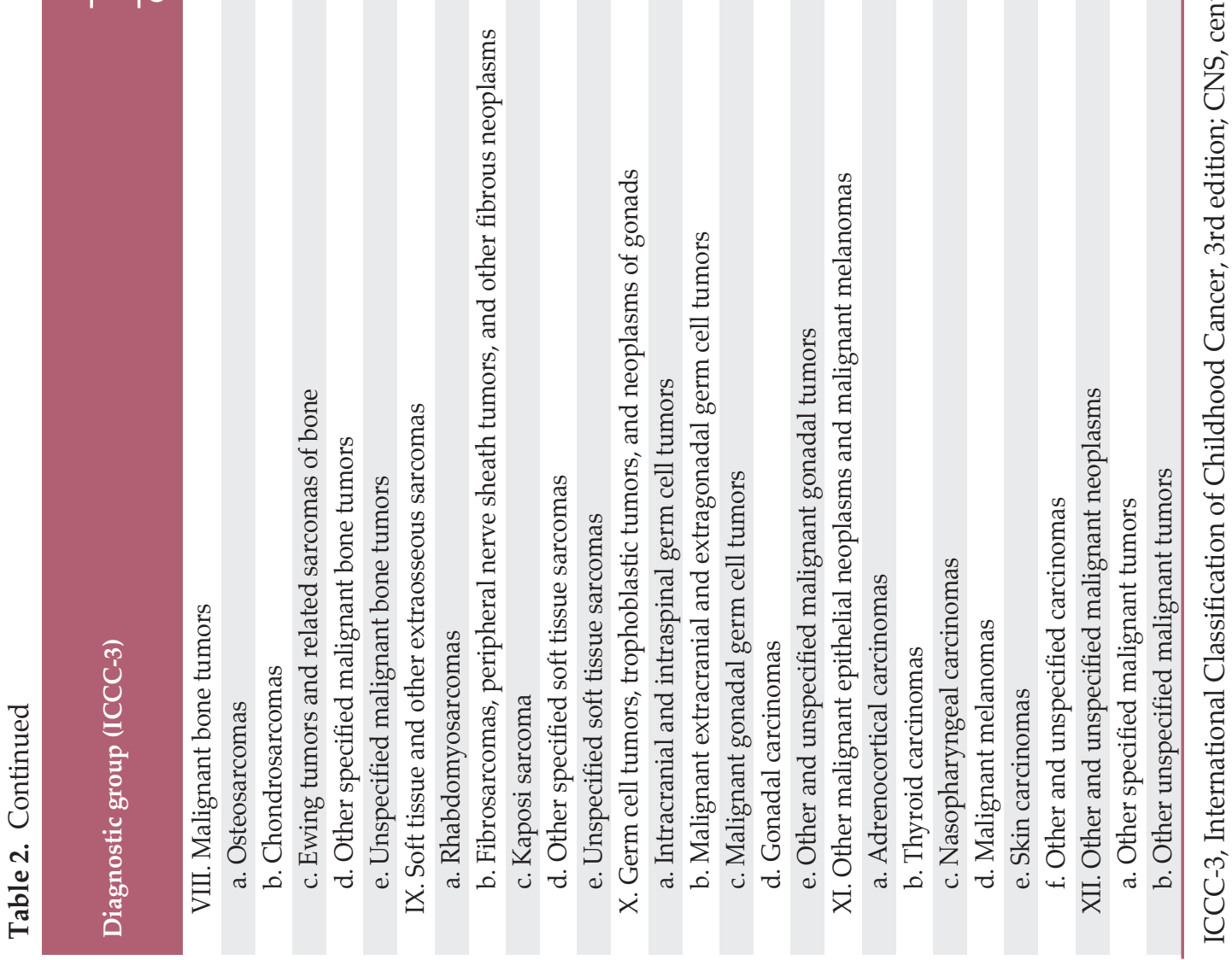
Both sexes
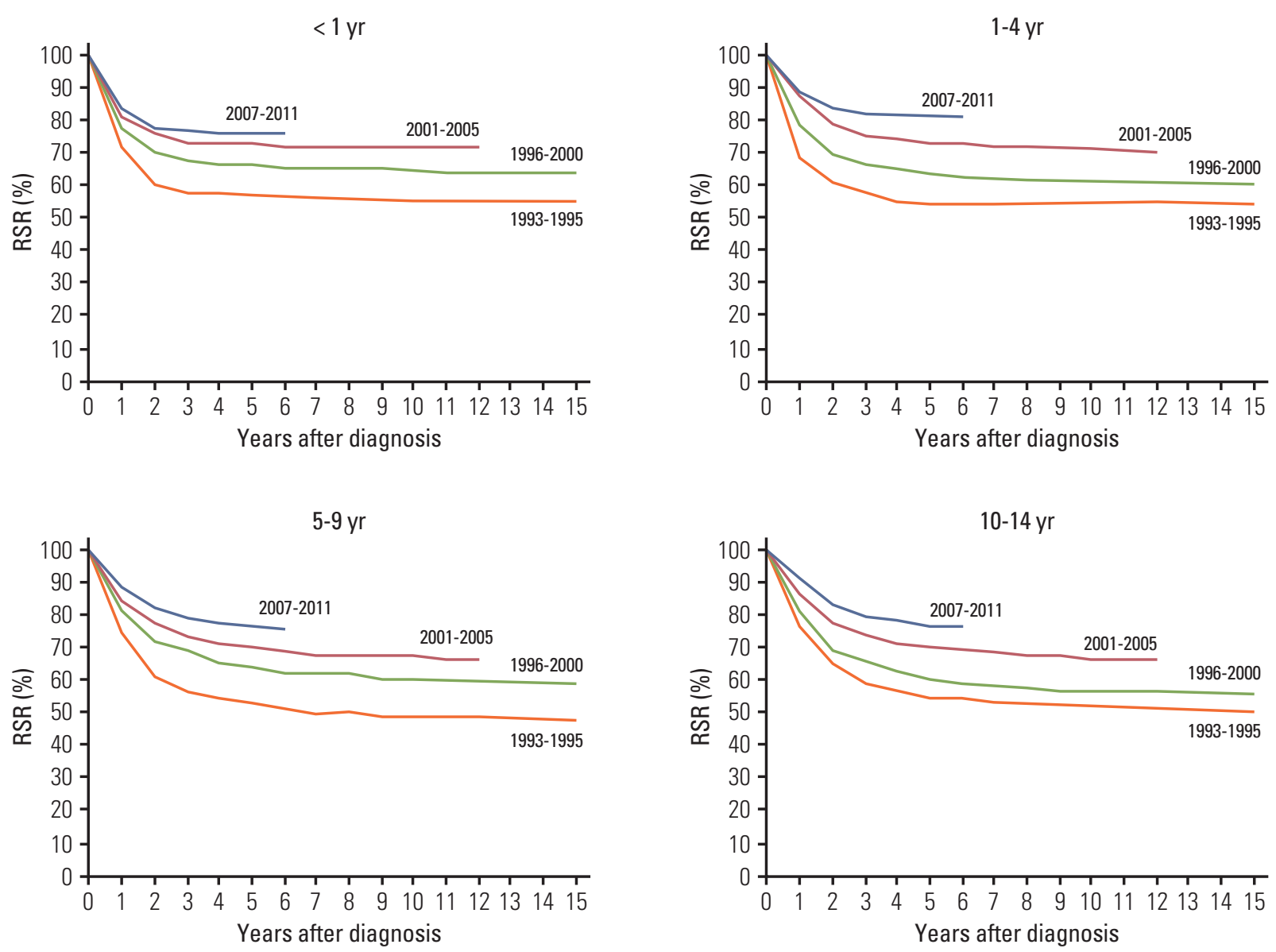

Fig. 3. Trends in relative survival rate (RSR) of childhood cancer in Korea according to age and the time period, 1993-2011. (A) Both sexes. (Continued to the next page)

\section{Discussion}

Epidemiologic studies of childhood cancer can provide useful information. By understanding the age distribution of cancer, we can identify the likely period of initiation of various tumors, which can provide insights regarding their etiology. For example, childhood cancer incidence rate is the highest in infancy when embryonal neoplasms such as neuroblastoma predominate, indicating that many childhood cancers result from aberrations in early developmental processes [14]. Further, as children may be more vulnerable to environmental exposures because their organs are developing rapidly. The studies of childhood cancer etiology will provide useful information in terms of evaluating the risks and causal roles of environmental factors. In addition, survival data are useful in the development of surveillance pro- grams for childhood cancer survivors, and survival trends can be used to evaluate progress in relation to treatment. However, there have been few nationwide epidemiological reports on childhood cancer providing reliable data over an extended period, particularly for Asian countries.

The KCCR is a national, population-based registry in South Korea. Annual incidence, survival, and prevalence rates of all cancers in Korea have been reported by the KCCR. In addition, a recent study provided epidemiological data on cancer in adolescents and young adults in Korea [11]. However, our study is the first to report cancer statistics for children younger than 15 years old in South Korea.

In comparison with other countries, our study found that the overall incidence of childhood cancer in South Korea was higher than that in other Asian countries such as China [15] and Thailand [16]. However, the incidence was lower than in countries in North America [2,7] and Europe [17]. The rea- 

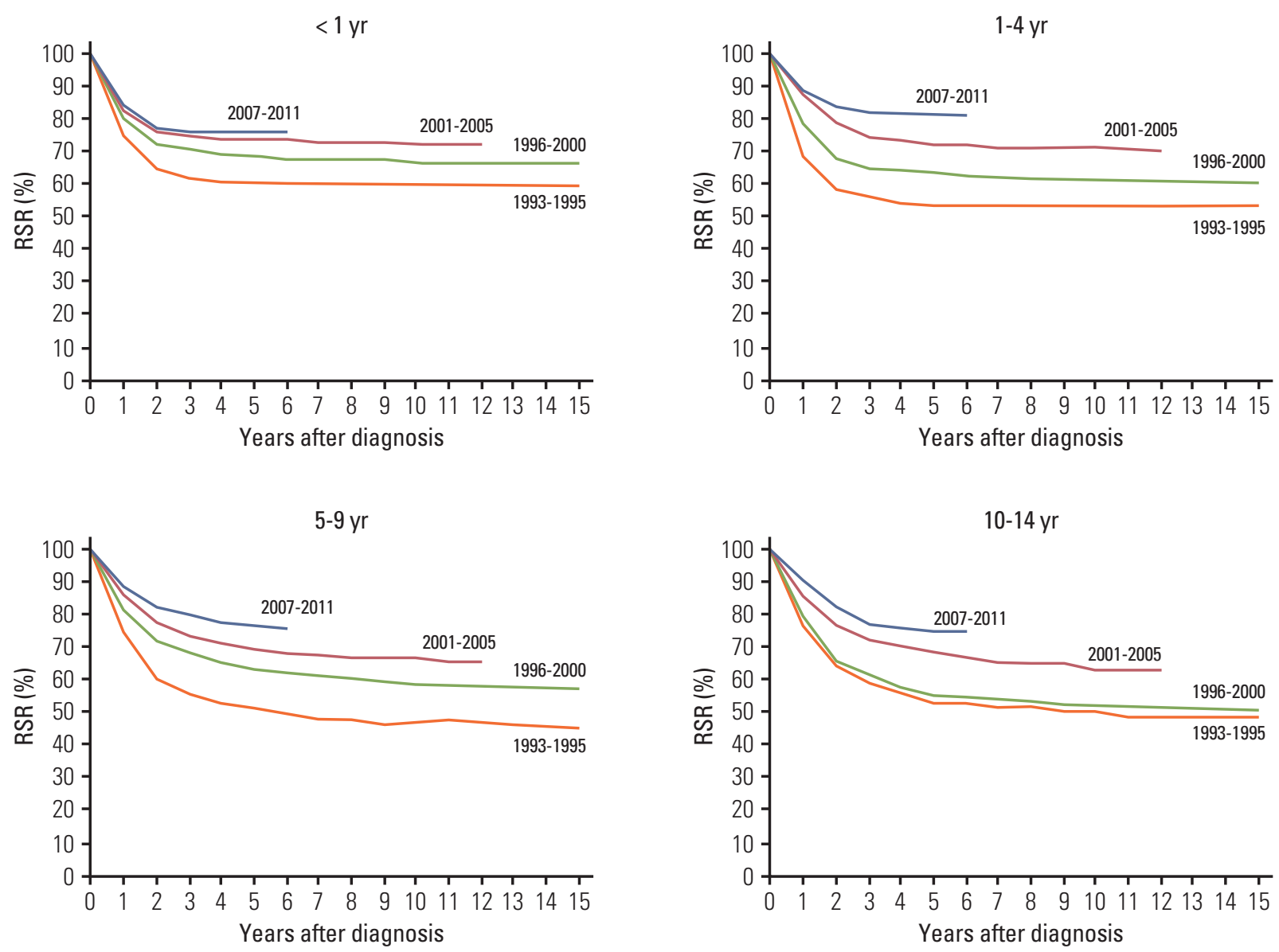

Fig. 3. (Continued from the previous page) (B) Male. (Continued to the next page)

son for this worldwide variability in childhood cancer incidence is unclear. In general, low- and middle-income countries have lower rates of childhood cancer than developed countries, which can be explained in part by underdiagnosis and under-reporting in these countries [18]. In the United States, childhood cancer incidence differs between racial and ethnic groups; in 2006-2010, the incidence rate was lowest in an American Indian/native Alaskan group (111.7 per million) and highest in a non-Hispanic White group (178.2 per million) [19]. These racial/ethnic differences may be attributable to differences in genetic predisposition as well as environmental exposure [20].

In our study, the proportions of childhood cancer subtypes differed between age groups. In infants (aged $<1$ year), the most frequent cancer was neuroblastoma / ganglioneuroblastoma, followed by lymphoid leukemia. In children older than 1 year of age, lymphoid leukemia was the most common can- cer.

The incidence rate of lymphoid leukemias was 28.3 per million in our study; in other countries, this ranged from 28 per million [17] to 40.8 per million [4]. In our study, incidence peaked around 3 years of age in both sexes (males, 55.7 per million; females, 60.4 per million). Similar peaks were also observed in data from white populations in the UK and United States in the early 20th century [21] and in recent studies conducted in Argentina [6]. The incidence of certain types of cancer is disproportionately high in some areas compared with overall incidence. For example, in sub-Saharan Africa, Burkitt lymphoma accounts for $25 \%-50 \%$ of all new childhood cancers, which can be explained by endemic Epstein-Barr virus [22].

In South Korea, incidence of childhood cancer increased by $2.4 \%$ annually from 1999 to 2011 . It is possible that improvements in diagnostic technologies are leading to 

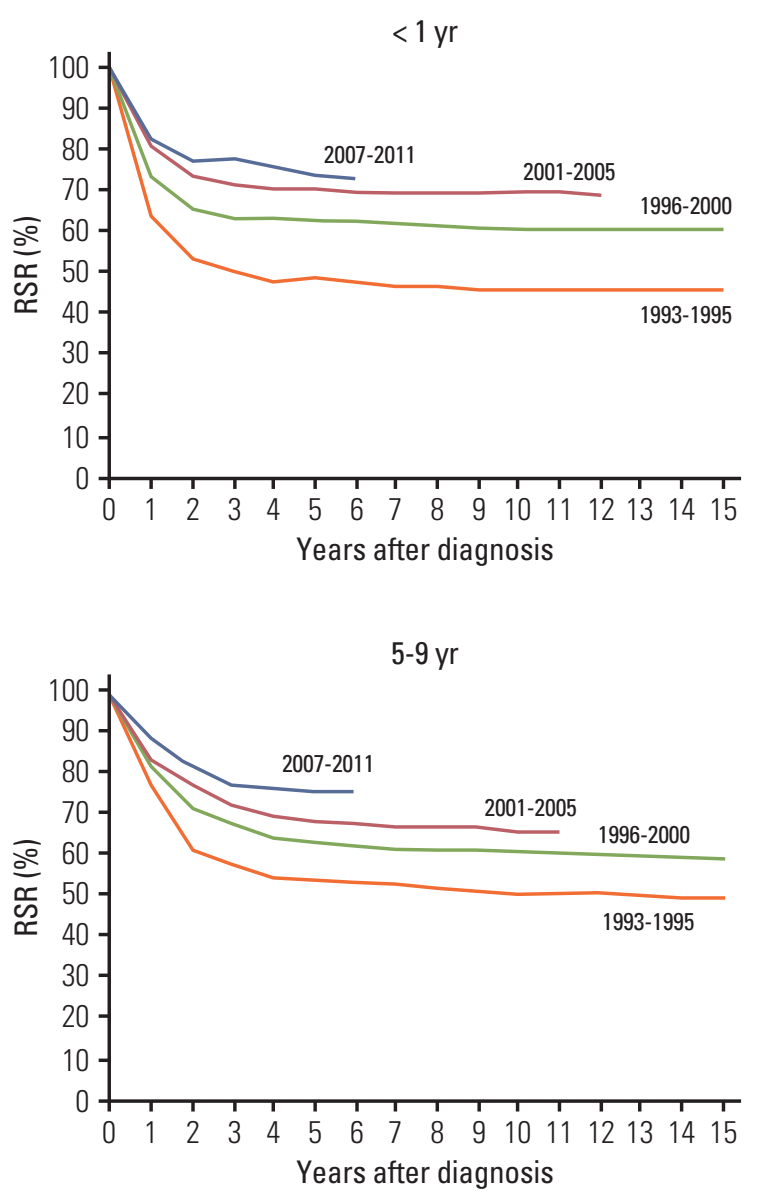

Fig. 3. (Continued from the previous page) (C) Female.

increased detection rates and thus increased incidence rates. Another possible reason for this increase is easy accessibility to hospital and treatment. Early studies in developed countries, based on data from the mid- to late-1970s, show increasing trends in incidence of childhood cancer [23,24]; however, more recent data from the United States (1992-2004) [2], Australia (1983-2006) [4], and Canada (1992-2006) [7] show a plateau in childhood cancer incidence.

In this study, the incidence of most cancer subtypes showed an increasing trend; however, the incidence of 'other and unspecified malignant neoplasms' decreased annually (APC, $-7.4 \%$ ). This can be explained in part by improvements in diagnostic methods and in the quality of characterization, leading to more specific diagnoses. In the study of cancer incidence in Korean adolescents and young adults (aged 15-29 years), cancer incidence also increased over time, and the rate of increment was steeper (APC, 6.3\%) [11].
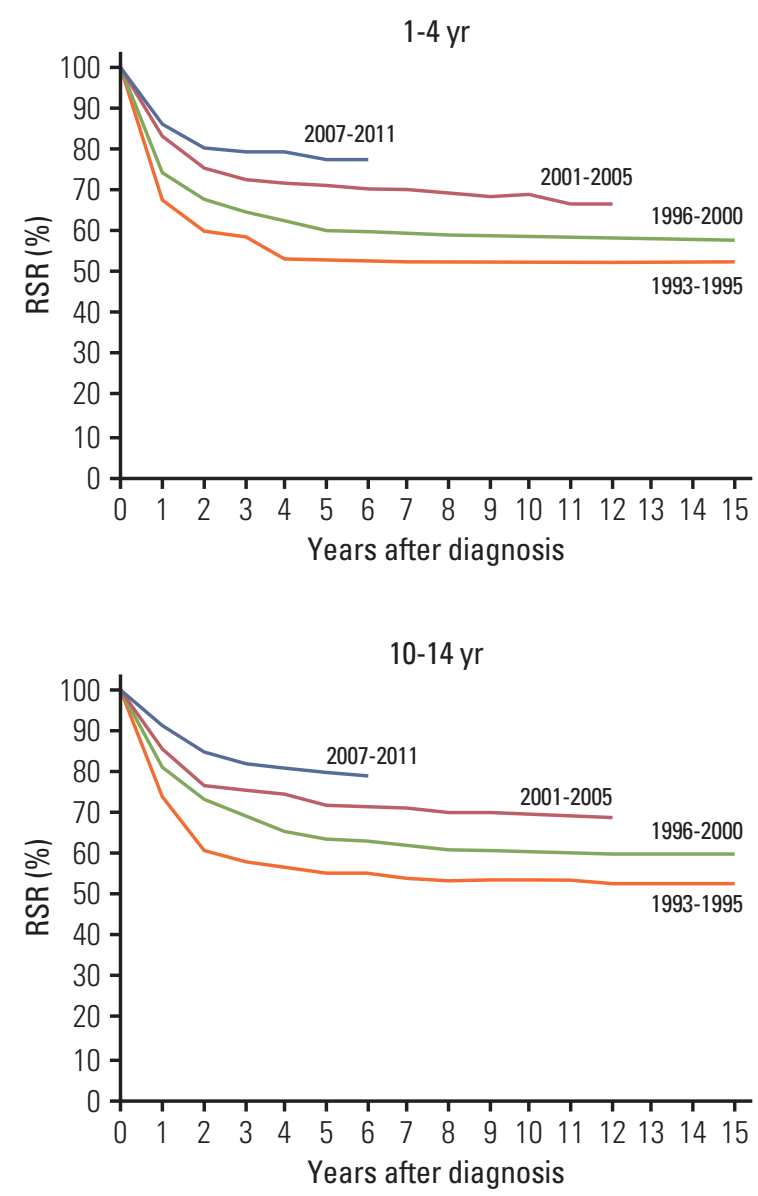

In this study, the overall 5-year cancer survival rate was 78.2\% for 2007-2011. This rate is lower than that of developed countries such as Italy [25] and the United States [19], but higher compared with developing countries in Asia such as China [15] and Thailand [16] (although the time periods are slightly different between these studies). These disparities may be caused by multiple factors, with a country's economic status being one contributor. In countries with a high economic status, children are more likely to have access to health insurance and to receive a timely diagnosis and high quality treatment and supportive care, and parents are more likely to have a high level of disease knowledge and adherence to therapy, all of which contribute to improved childhood cancer survival rates [20].

The current survival rate in South Korea is similar to that of the United States from 1995 to 1999 [23] and of Britain from 1998 to 2005 [8]. In the United States, the 5-year survival rate 
increased from $79.3 \%$ in $1995-1999$ to $83.1 \%$ in $2004-2010$ $[19,23]$. This implies that improvements in the survival rate are possible in South Korea, and efforts should be made to achieve this.

In this study, survival rates varied between cancer subtype, increasing steadily from 1993-2011 for lymphoid leukemias and neuroblastoma, but with little change since 2005 for CNS tumors, soft tissue sarcoma, or osteosarcoma. Efforts to improve survival should be continued, especially for cancers with low survival rates such as CNS tumors.

In this study, it was not possible to describe long-term trends for incidence and survival due to the relatively short existence of the official population-based cancer registry in Korea. Another limitation is that information on cancer stage or treatment was not included.

\section{Conclusion}

This study provides reliable information on incidence and survival trends for childhood cancers, providing a more comprehensive understanding of these cancers. The results from this study will be useful for professionals related with childhood cancer in the development of optimized healthcare services for childhood cancer patients and survivors.

\section{Conflicts of Interest}

Conflict of interest relevant to this article was not reported.

\section{Acknowledgments}

This work was supported by a research grant from the National Cancer Center (No. 1310220) and a Korea Childhood Leukemia Foundation 2013 Grant (No. 201302).

\section{References}

1. Siegel R, DeSantis C, Virgo K, Stein K, Mariotto A, Smith T, et al. Cancer treatment and survivorship statistics, 2012. CA Cancer J Clin. 2012;62:220-41.

2. Linabery AM, Ross JA. Trends in childhood cancer incidence in the U.S. (1992-2004). Cancer. 2008;112:416-32.

3. Michel G, von der Weid NX, Zwahlen M, Redmond S, Strippoli MP, Kuehni CE, et al. Incidence of childhood cancer in Switzerland: the Swiss Childhood Cancer Registry. Pediatr Blood Cancer. 2008;50:46-51.

4. Baade PD, Youlden DR, Valery PC, Hassall T, Ward L, Green AC, et al. Trends in incidence of childhood cancer in Australia, 1983-2006. Br J Cancer. 2010;102:620-6.

5. Shin HR, Won YJ, Jung KW, Kong HJ, Yim SH, Lee JK, et al. Nationwide cancer incidence in Korea, 1999 2001; first result using the national cancer incidence database. Cancer Res Treat. 2005;37:325-31.

6. Moreno F, Loria D, Abriata G, Terracini B; ROHA network. Childhood cancer: incidence and early deaths in Argentina, 2000-2008. Eur J Cancer. 2013;49:465-73.

7. Mitra D, Shaw AK, Hutchings K. Trends in incidence of childhood cancer in Canada, 1992-2006. Chronic Dis Inj Can. 2012;
32:131-9.

8. Basta NO, James PW, Gomez-Pozo B, Craft AW, McNally RJ. Survival from childhood cancer in northern England, 19682005. Br J Cancer. 2011;105:1402-8.

9. Steliarova-Foucher E, Stiller C, Lacour B, Kaatsch P. International Classification of Childhood Cancer, third edition. Cancer. 2005;103:1457-67.

10. Jung KW, Won YJ, Kong HJ, Oh CM, Lee DH, Lee JS. Cancer statistics in Korea: incidence, mortality, survival, and prevalence in 2011. Cancer Res Treat. 2014;46:109-23.

11. Moon EK, Park HJ, Oh CM, Jung KW, Shin HY, Park BK, et al. Cancer incidence and survival among adolescents and young adults in Korea. PLoS One. 2014;9:e96088.

12. Brenner H, Gefeller O. Deriving more up-to-date estimates of long-term patient survival. J Clin Epidemiol. 1997;50:211-6.

13. Dickman PW, Sloggett A, Hills M, Hakulinen T. Regression models for relative survival. Stat Med. 2004;23:51-64.

14. Scheurer ME, Bondy ML, Gurney JG. pidemiology of childhood cancer. In: Pizzo PA, Poplack DG, editors. Principles and practice of pediatric oncology. 6th ed. Philadelphia, PA: Wolters Kluwer Health/Lippincott Williams \& Wilkins; 2015. p. 
$2-16$.

15. Bao PP, Zheng Y, Gu K, Wang CF, Wu CX, Jin F, et al. Trends in childhood cancer incidence and mortality in urban Shanghai, 1973-2005. Pediatr Blood Cancer. 2010;54:1009-13.

16. Wiangnon S, Veerakul G, Nuchprayoon I, Seksarn P, Hongeng $\mathrm{S}$, Krutvecho T, et al. Childhood cancer incidence and survival 2003-2005, Thailand: study from the Thai Pediatric Oncology Group. Asian Pac J Cancer Prev. 2011;12:2215-20.

17. Kaatsch P. Epidemiology of childhood cancer. Cancer Treat Rev. 2010;36:277-85.

18. Magrath I, Steliarova-Foucher E, Epelman S, Ribeiro RC, Harif M, Li CK, et al. Paediatric cancer in low-income and middleincome countries. Lancet Oncol. 2013;14:e104-16.

19. Ward E, DeSantis C, Robbins A, Kohler B, Jemal A. Childhood and adolescent cancer statistics, 2014. CA Cancer J Clin. 2014; 64:83-103.

20. Chow EJ, Puumala SE, Mueller BA, Carozza SE, Fox EE, Horel $S$, et al. Childhood cancer in relation to parental race and eth- nicity: a 5-state pooled analysis. Cancer. 2010;116:3045-53.

21. Brown WM, Doll R. Leukaemia in childhood and young adult life. Br Med J. 1961;1:981-8.

22. Parkin DM, Sitas F, Chirenje M, Stein L, Abratt R, Wabinga H. Part I: Cancer in Indigenous Africans: burden, distribution, and trends. Lancet Oncol. 2008;9:683-92.

23. Linabery AM, Ross JA. Childhood and adolescent cancer survival in the US by race and ethnicity for the diagnostic period 1975-1999. Cancer. 2008;113:2575-96.

24. Kaatsch P, Steliarova-Foucher E, Crocetti E, Magnani C, Spix C, Zambon P. Time trends of cancer incidence in European children (1978-1997): report from the Automated Childhood Cancer Information System project. Eur J Cancer. 2006;42: 1961-71.

25. Dama E, Pastore G, Mosso ML, Maule MM, Zuccolo L, Magnani $\mathrm{C}$, et al. Time trends and prognostic factors for survival from childhood cancer: a report from the Childhood Cancer Registry of Piedmont (Italy). Eur J Pediatr. 2006;165:240-9. 